\title{
New Faces at the Polls for New Hampshire Presidential Primary
}

KENNETH M. JOHNSON

$\mathrm{T}$ There will be many new faces at the polls on January 8th for the New Hampshire Presidential Primary. Between 2001 and 2006, at least 207,000 people moved to New Hampshire from elsewhere in the United States and 188,000 left the state. With only 1,315,000 residents, this has produced considerable turnover in the pool of potential voters.

Approximately 145,000 of the recent in-migrants to New Hampshire are of voting age and an additional 86,000 New Hampshire residents had their 18th birthday in the past five years. Together these two groups represent 232,000 potential new voters. With approximately 987,000 citizens of voting age in New Hampshire, these 232,000 are 23.5 percent of the potential voter pool for the primary. Some will not register or vote, but those that do represent a substantial proportion of those likely to cast ballots in the upcoming New Hampshire presidential primary.

Approximately 128,000 of the people who left New Hampshire for other states between 2001 and 2006 were of voting age. The voting rolls were further thinned by 48,700 deaths of voting age individuals during the period. Combining these groups, 177,000 individuals of voting age who were in New Hampshire five years ago are now gone.

\section{Characteristics of Recent Migrants}

The high turnover in the voting age population comes as little surprise. Nearly 57 percent of New Hampshire residents were born outside the state. The U.S. average is 40 percent. Only seven states have a larger proportion of their residents born outside the state.

Almost 25 percent of New Hampshire residents were born in Massachusetts, and Internal Revenue Service (IRS) data indicate that the largest source of new migrants to New Hampshire is the Boston metropolitan area. Slightly more than 78,000 people moved to New Hampshire from Boston between 2001 and 2006 (Figure 1). Households moving to New Hampshire from metropolitan Boston tend to be relatively affluent with a mean income higher than existing New Hampshire households or those leaving the state. New Hampshire gained an additional 37,500 migrants from the rest of New England. In-migrants from New England also earned more than those leaving, though the income difference was much more modest.

New Hampshire also gained migrants and potential voters from other regions of the United States. The South was the largest source with 32,600 in-migrants. Additional streams of in-migrants came from the MidAtlantic states $(28,200)$ and from the Midwest and West $(29,000)$.

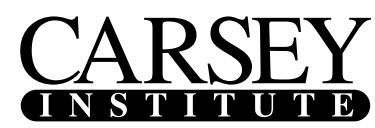

Building KNOWLEdge for FAmilies AND COMMUNities IN THE 21ST CENTURY
Huddleston Hall, 73 Main Street, Durham, NH 03824

(603) 862-2821 • www.carseyinstitute.unh.edu

This brief is part of a series of Carsey Institute Reports on Changes in New England. 
Figure 1: Migration to AND from NeW Hampshire from Other U.S. Regions, 2001-2006

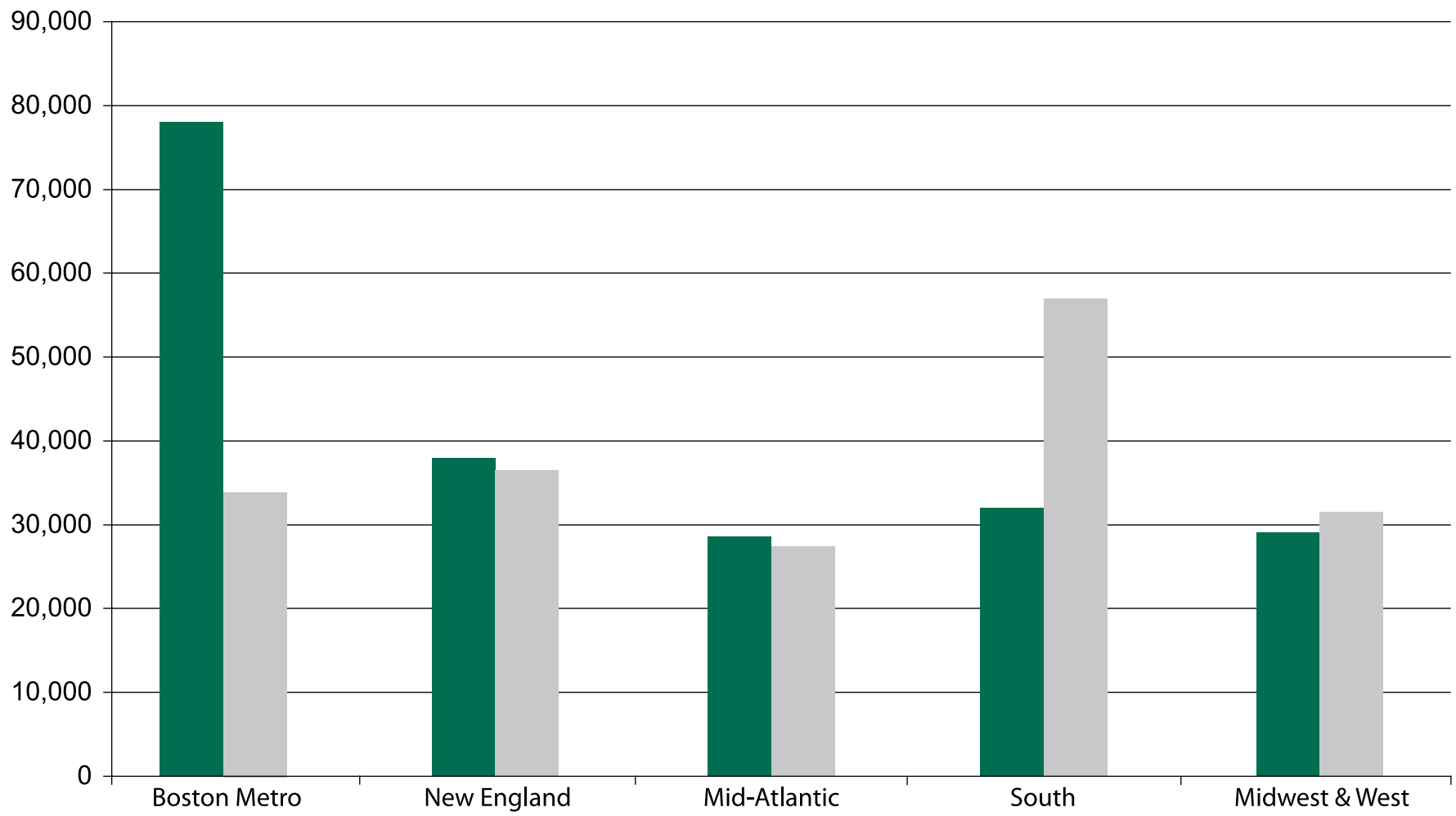

The largest stream of out-migrants, including many retirees, went to the South $(56,000)$. There was also a significant outflow to the Boston metropolitan area as well as to the Mid-Atlantic, West and Midwest. In each case, those leaving New Hampshire earned less than those moving into the Granite State.

\section{Age Specific Net Migration}

The IRS migration data do not provide demographic information about the migration streams to and from New Hampshire. However, age specific net migration estimates provide hints about who is coming to New Hampshire. The state received a significant inflow of 30- to 49-year-olds and children suggesting an inflow of families between 2000 and 2005 (Figure 2), Data from New Hampshire for the 1990s and national data for urban fringe counties like those in southern New Hampshire reflect similar findings. There is also a net in-migration of those 50 to 69 reflecting retirement age migration to New Hampshire's abundant recre- ational and amenity areas. However, these results must be interpreted with caution because they are only estimates.

\section{Historical Primary but New Voters}

The population of New Hampshire is among the most mobile in the United States. More than 23 percent of the voting age population in New Hampshire will have their first opportunity to cast a primary ballot in the upcoming election. New Hampshire is receiving a significant stream of families and retirement age migrants who are relatively affluent. Most of the in-migrants come from the Boston metropolitan region or from elsewhere in New England, but there are sizeable flows from other regions of the nation as well. Thus, many potential voters in the New Hampshire Primary are new to the process and to the state. 


\section{CARSEY INSTITUTE}

Figure 2: New Hampshire Estimated Age Specific Net Migration, 2000-2005

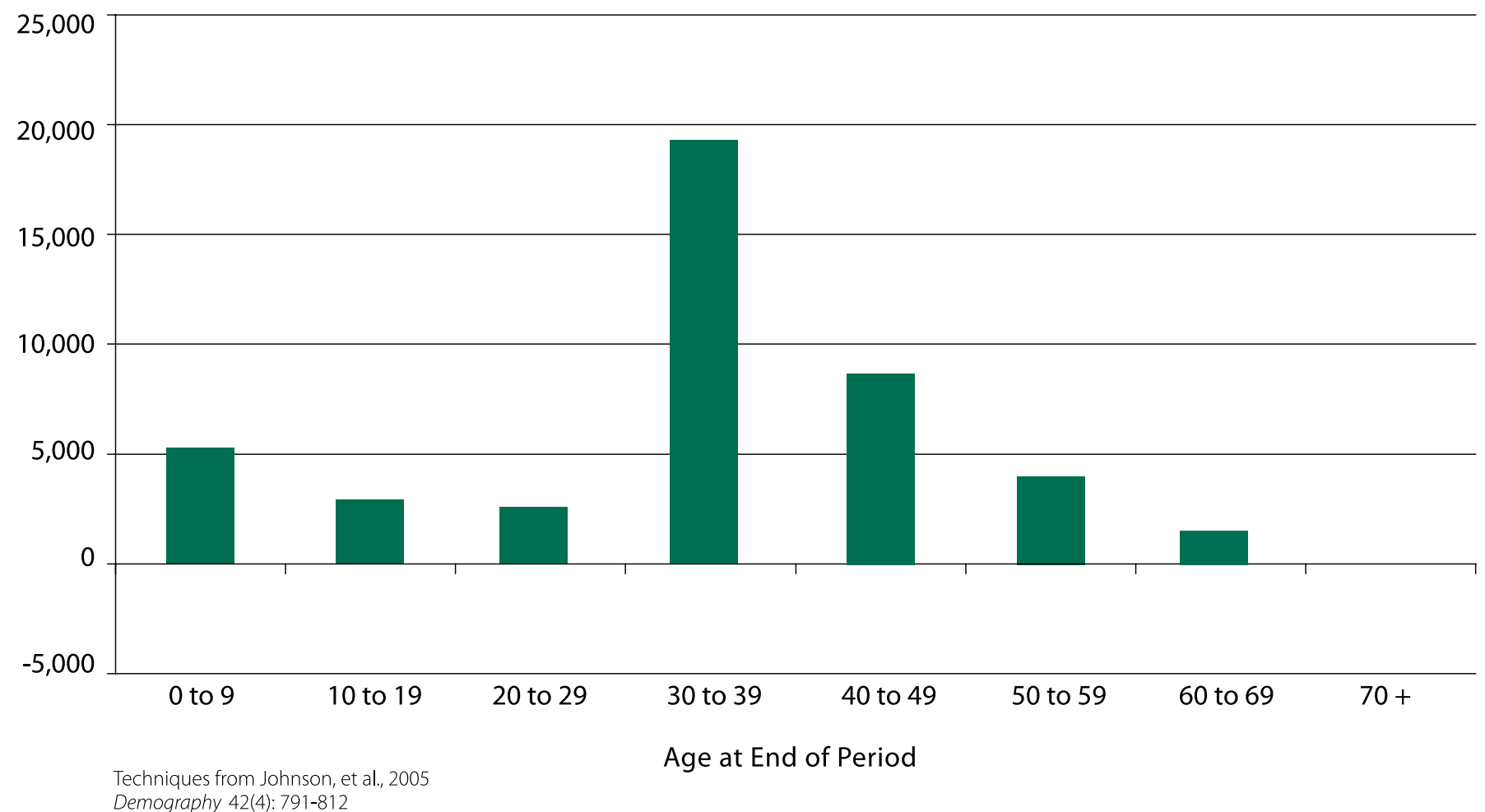

ABOUT THIS FACT SHEET

This brief provides supplemental analysis of data presented in the Carsey Institute Report, The Changing Faces of New Hampshire: Recent Demographic Trends in the Granite State by Kenneth M. Johnson, available at www.carseyinstitute. unh.edu. Detailed analysis of recent New Hampshire demographic trends together with a description of the data and methods used here are included in the Carsey report.

\section{A BOUT THE AUTHOR}

This fact sheet and the Carsey report it supplements were written by Kenneth M. Johnson, Ph.D, Senior Demographer at the Carsey Institute and a Visiting Professor of Sociology at the University of New Hampshire. Dr. Johnson is a nationally recognized expert on U.S. demographic trends. Allison Churilla of the Carsey Institute provided valuable research assistance on the project. 